\title{
On the impact of global interactions on the structure of metallic glasses
}

\author{
Martin E. Stiehler*, Mark R. Jolly, Konstantinos Georgarakis \\ School of Aerospace, Transport and Manufacturing, Cranfield University, Cranfield MK43 OAL, UK
}

\begin{abstract}
The influence of global interactions between the static atomic structure and the valence electrons on structure formation in binary $\mathrm{Al}-(\mathrm{Ni}, \mathrm{Cu}, \mathrm{Zr}), \mathrm{Zr}-(\mathrm{Ni}, \mathrm{Cu})$ and ternary $\mathrm{Al}-(\mathrm{Ni}, \mathrm{Cu})-\mathrm{Zr}$ metallic glasses is investigated over wide concentration ranges and discussed in terms of a Hume-Rothery-like theory by analysing and comparing data available in the literature. The results suggest that global interactions lead to an improvement of thermal stability and glass-forming ability. A complete understanding of structure formation in the considered alloys is assumed to be possible only by taking into account both local and global effects.
\end{abstract}

Keywords: Aluminum alloys, Zirconium alloys, Metallic glasses, Electronic structure, Glass-forming ability, Hume-Rothery

\section{Introduction}

Metallic glasses are a promising class of materials for versatile future applications[1,2]. However, the small critical casting thicknesses still limit the dimension of parts engineered from these materials. Although Zr-based metallic glasses exhibit comparatively high casting thicknesses a comprehensive understanding of the conditions necessary for good glass-forming ability (GFA) is still missing. Most often only effects on the local level, i.e. due to clusters, chemical short range order (CSRO) or medium range order (MRO), are considered. On the other hand it is known that global interactions between the static atomic structure and the valence electrons, i.e. the electronic structure, play an important role during structure formation in liquid and amorphous (a) systems [3-11].

The influence of global effects was first recognised by HumeRothery in crystalline (c) solid-solutions by scaling their phase diagrams not versus composition but the mean valence $\bar{Z}$ (measured in electrons per atom, e/a) simply taking the usual valence of the components according to their position in the periodic table[12]. It became obvious that these systems exhibit the same sequence of crystalline phases as function of $\bar{Z}$. An explanation of this correlation was given by Jones in terms of the dimensions of the Fermi sphere and Brillouin zones relative to each other[13]. Since then the model was refined and put on the basis of state-of-the-art solid state theory [14, 15] as well as adapted to be applicable as guide in the search for new materials with promising applications and to understand phase stability in many different classes of materials [7, 15-22]. These include amorphous alloys to which the ideas were first transferred by Nagel and Tauc[23] and later elaborated on by several authors[3, 4, 6-11].

\footnotetext{
*Corresponding author.

Email address: martin.stiehler@cranfield.ac.uk (Martin E. Stiehler)
}

In this global description instead of looking at single electrons and local bonds the subsystem of the valence electrons as a whole is considered and characterised by the Fermi sphere with the diameter

$$
2 k_{\mathrm{F}}=2 \sqrt[3]{3 \pi^{2} \bar{Z} \frac{1}{\bar{\Omega}_{0}}},
$$

where $\bar{\Omega}_{0}$ is the mean atomic volume of the alloy[24]. The energy of the highest occupied electronic states, at the edge of the Fermi sphere, is called Fermi energy $E_{\mathrm{F}}$. The structure on the other hand is characterised by the Brillouin zone in c-systems or pseudo-Brillouin zone in a-systems, respectively. The latter is always spherical and characterised by its diameter $Q_{\mathrm{p}}$ which, in metallic systems, is identical with the position of the principal peak, i.e. the modulus of the according scattering vector, in the static structure factor $S(Q)$ [3]. Due to (pseudo-)Bragg scattering of valence electrons a rearrangement of electronic states to both higher and, more importantly, to lower energies is caused. This leads to the occurrence of gaps (c-systems) or pseudogaps, i.e. local minima, (a-systems) bordered by maxima in the electronic density of states (DOS)[25, 26]. If optimally $E_{\mathrm{F}}$ lies close to the centre of the (pseudo)gap, only the states shifted to lower energies are occupied and the energy of the whole system is decreased, i.e. the system is more stable than without the (pseudo)gap. If in an alloy the composition is changed generally the mean valence and therefore $E_{\mathrm{F}}$ changes as well. Accordingly, $E_{\mathrm{F}}$ does not fall in the (pseudo)gap any more and the system loses its advantage. It is now favourable for the alloy to change its structure to re-achieve the advantage which explains Hume-Rothery's original observation[13-15]. Due to the lack of different phases a-systems react on a change of $2 k_{\mathrm{F}}$ by an according change of $Q_{\mathrm{p}}$ which has been shown experimentally in a large number of so-called "simple" a-alloys with only s- and p-states present at $E_{\mathrm{F}}$ [3]. The matching of $2 k_{\mathrm{F}}$ and $Q_{\mathrm{p}}$ is referred to as resonance[27].

If the alloys contain transition metals (TM) the assumption 
that it is only the static structure that is adjusting to electronic constraints had to be to be dropped[28]. Especially in the case of binary a-Al-TM alloys it was argued that $2 k_{\mathrm{F}}$ can be influenced by hybridisation effects between Al-sp- and TM-d-states at $E_{\mathrm{F}}$ which can be described by an effective valence of $\mathrm{Al}$ or the TM[28-30]. This flexibility of the electronic system provides a further degree of freedom for the system to achieve its most favourable state[4, 7, 10, 31]. Furthermore, hybridisation has been demonstrated to cause effective valences already for pure TM[32-34]. In this respect a valence of $Z=1.5$ was found to be appropriate for the complete row of the $3 \mathrm{~d}-\mathrm{TM}$, including $\mathrm{Ca}$ and $\mathrm{Cu}$ [33]. For $\mathrm{Zr}$, a 4d-TM, $Z$ was assumed to lie between 1 and 2[32] and has been assessed successfully with, again, 1.5 in the context of amorphous alloys[5]. For the remainder of this paper we will therefore adopt $Z=1.5$ for $\mathrm{Ni}, \mathrm{Cu}$ and $\mathrm{Zr}$.

The presence of TM-d-states at $E_{\mathrm{F}}$, on the other hand, causes high values of the DOS at $E_{\mathrm{F}}, N\left(E_{\mathrm{F}}\right)$, which often impedes the easy identification of a pseudogap[6]. In principal the measured $N\left(E_{\mathrm{F}}\right)$ has to be compared to calculations without the pseudogap, $N_{0}\left(E_{\mathrm{F}}\right)$, which can be done easily only for simple a-alloys[3]. However, other things being equal, even a small reduction of $N_{0}\left(E_{\mathrm{F}}\right)$, i.e. a small energy gain, maybe decisive for the stabilisation of a specific structure of the alloy[3, 6]. In general, DOS features like pseudogaps are the result of highly intertwined structural and electronic properties[10, 30, 35]. A careful angular-momentum projected analysis of the DOS from experimental as well as theoretical considerations is inevitable. Experimentally photo-electron spectroscopy (PES) as well as inverse photo-electron spectroscopy (IPES) are necessary to obtain the exact shape of the DOS in the vicinity of $E_{\mathrm{F}}$. If, for example, $E_{\mathrm{F}}$ is not located in the centre of the pseudogap and only PES results are considered, it may appear that $E_{\mathrm{F}}$ is mistakenly related to the aforementioned maximum below the pseudogap and not to the pseudogap itself leading to contradictory assumptions about the presence of resonance[36, 37].

Complementary to the discussion of a-systems in $k$-space there is also an indication of the resonance in $r$-space in form of the so-called spherical periodic order (SPO)[3]. If the radii

$$
r_{n}=\left(\frac{5}{4}+n\right) \cdot \frac{2 \pi}{Q_{\mathrm{p}}} \quad(n=0,1,2, \ldots)
$$

of the coordination spheres around any chosen atom resonantly match with the wavelength $\lambda_{\mathrm{Fr}}=2 \pi / 2 k_{\mathrm{F}}$ of the Friedel oscillations of the effective pair potential a characteristic sequence of peaks in the pair correlation function according to

$$
r_{n}=\left(\frac{5}{4}+n\right) \cdot \lambda_{\mathrm{Fr}} \quad \text { with } \quad n=0,1,2, \ldots
$$

can be observed as a fingerprint of the resonance[3]. In that situation an a-system is especially stable since the atoms are located in the minima of the effective pair potential[3, 38-40]. Alternatively, the SPO can be understood as the result of a selforganisation between the atoms and the valence electrons during structure formation to adjust the interatomic distances for an optimised pseudo-Bragg scattering in order to enhance the pseudogap $[25,26]$. It has to be noted that the SPO, in its current form, does not distinguish between the different species in an alloy and hence cannot explain the occurrence of the individual partial pair correlation functions. In this regard, the SPO is a purely topological but nevertheless powerful description of the interplay of order and energetic stabilisation in the system under consideration.

In the present study the impact of global effects on structure formation in a-Al-(Ni,Cu, Zr), a-Zr-(Ni,Cu) and its implications for the ternary systems a-Zr- $(\mathrm{Ni}, \mathrm{Cu})-\mathrm{Al}$ is investigated. This is done by comparing the positions of the peak centres $Q_{\mathrm{p}}$ of the principal peak in the respective structure factors $S(Q)$ with $2 k_{\mathrm{F}}$ calculated using appropriate assumptions for the valences $Z$ of the elements involved as outlined above as well as elaborated in more detail in the following sections. In the case of the binary $\mathrm{a}-\mathrm{Zr}-(\mathrm{Ni}, \mathrm{Cu})$ alloys correlations with further properties are explored in order to substantiate the suggested global influences, i.e. the presence of resonance. All experimental data discussed is taken from the literature.

\section{Binary systems}

The ternary systems $\mathrm{Zr}-(\mathrm{Ni}, \mathrm{Cu})-\mathrm{Al}$ are bordered by the binary systems $\mathrm{Al}-(\mathrm{Ni}, \mathrm{Cu}), \mathrm{Al}-\mathrm{Zr}$ and $\mathrm{Zr}-(\mathrm{Ni}, \mathrm{Cu})$. We therefore begin our discussion with the latter four systems. Table 1 lists

\begin{tabular}{cccc}
\hline \hline element & $\begin{array}{c}r_{\text {at }} \\
(\mathrm{nm})\end{array}$ & $\begin{array}{c}\Omega_{0} \\
\left(\AA^{3}\right)\end{array}$ & $\begin{array}{c}\Delta H_{A-\mathrm{Zr}}^{\mathrm{mix}} \\
(\mathrm{kJ} / \mathrm{mol})\end{array}$ \\
\hline $\mathrm{Al}$ & 0.141 & 16.61 & -44 \\
$\mathrm{Ni}$ & 0.126 & 10.94 & -49 \\
$\mathrm{Cu}$ & 0.126 & 11.78 & -23 \\
$\mathrm{Zr}$ & 0.158 & 23.28 & - \\
\hline \hline
\end{tabular}

Table 1: Data of the chemical elements considered in the present study: atomic radius $\left(r_{\mathrm{at}}\right)$ [41], atomic volume $\left(\Omega_{0}\right)$ (calculated from mass density[42] and atomic mass [43]) and enthalpy of mixing with $\mathrm{Zr}\left(\Delta H_{A-\mathrm{Zr}}^{\mathrm{mix}}\right)$ using the Miedema model[44].

for the chemical elements involved in this study data relevant for the subsequent discussion (atomic radius $r_{\text {at }}$, atomic volume $\Omega_{0}$, enthalpy of mixing with $\mathrm{Zr} \Delta H_{A-\mathrm{Zr}}^{\mathrm{mix}}$ ). Table 2 lists for the alloys under discussion the method of production, their thicknesses (where appropriate), the physical quantities considered, the symbols used in Figs. 1 and 2 as well as the respective reference to the literature. Open, half-open and closed symbols are used for thin film samples, mechanically alloyed samples and melt-spun/bulk samples, respectively.

\subsection{Binary a-Al-(Ni,Cu,Zr) alloys}

Figure 1 shows the positions $Q_{\mathrm{p}}$ of the principal peaks in $S(Q)$ for binary a-Al-(Ni,Cu,Zr) alloys. The lines in Fig. 1 represent calculations of $2 k_{\mathrm{F}}$ using Eq. (1). For these calculations the knowledge of the mean atomic volumes $\bar{\Omega}_{0}$ are necessary. Due to the absence of experimental values $\bar{\Omega}_{0}$ were calculated as an concentration-weighted average of the values of the pure crystalline elements (Tab. 1) under the assumption that the values in the a-state are close those of the c-state and stay constant during alloying. Especially for Al-Ni it is known that the latter 


\begin{tabular}{|c|c|c|c|c|c|c|}
\hline mat. & prep. & thick. & quantity & fig. & sym. & ref. \\
\hline$\overline{\mathrm{Al}-\mathrm{Ni}}$ & f.e. & $\approx 30 \mathrm{~nm}$ & $Q_{\mathrm{p}}$ & $1 \mathrm{a}$ & 0 & [45] \\
\hline $\mathrm{Al}-\mathrm{Ni}$ & f.e. & $\approx 30 \mathrm{~nm}$ & $Q_{\mathrm{p}}$ & $1 \mathrm{~b}$ & $\square$ & [46] \\
\hline$\overline{\mathrm{Al}-\mathrm{Cu}}$ & f.e. & $\approx 30 \mathrm{~nm}$ & $Q_{\mathrm{p}}$ & $1 \mathrm{c}$ & 0 & [47] \\
\hline$\overline{\mathrm{Al}-\mathrm{Zr}}$ & b.m. & - & $Q_{\mathrm{p}}$ & $1 \mathrm{c}$ & $\checkmark$ & [48] \\
\hline $\mathrm{Al}-\mathrm{Zr}$ & s.d. & N/A & $Q_{\mathrm{p}}$ & $1 \mathrm{c}$ & 0 & [49] \\
\hline $\mathrm{Al}-\mathrm{Zr}$ & s.d. & N/A & $Q_{\mathrm{p}}$ & $1 \mathrm{c}$ & $\triangle$ & [50] \\
\hline $\mathrm{Al}-\mathrm{Zr}$ & b.m. & - & $Q_{\mathrm{p}}$ & $1 \mathrm{c}$ & $\Delta$ & [51] \\
\hline $\mathrm{Al}-\mathrm{Zr}$ & b.m. & - & $Q_{\mathrm{p}}$ & $1 \mathrm{c}$ & D & [52] \\
\hline $\mathrm{Al}-\mathrm{Zr}$ & b.b. & - & $Q_{\mathrm{p}}$ & $1 \mathrm{c}$ & (1) & [53] \\
\hline $\mathrm{Al}-\mathrm{Zr}$ & b.m. & - & $Q_{\mathrm{p}}$ & $1 \mathrm{c}$ & $\theta$ & [54] \\
\hline $\mathrm{Al}-\mathrm{Zr}$ & s.d. & $\approx 2 \mu \mathrm{m}$ & $Q_{\mathrm{p}}$ & $1 \mathrm{c}, 4$ & $\triangleleft$ & [55] \\
\hline $\mathrm{Al}-\mathrm{Zr}$ & s.d. & $\approx 2 \mu \mathrm{m}$ & $Q_{\mathrm{p}}$ & $1 \mathrm{c}, 4$ & $\nabla$ & [56] \\
\hline $\mathrm{Ni}-\mathrm{Zr}$ & m.s. & N/A & $Q_{\mathrm{p}}, T_{\mathrm{X}}$ & $2 \mathrm{c}, \mathrm{g}$ & - & [57] \\
\hline $\mathrm{Ni}-\mathrm{Zr}$ & m.s. & $30 \mu \mathrm{m}$ & $\Omega_{0}, Q_{\mathrm{p}}$ & $2 \mathrm{a}, \mathrm{c}$ & & [58] \\
\hline $\mathrm{Ni}-\mathrm{Zr}$ & m.s. & $20-50 \mu \mathrm{m}$ & $\Omega_{0}, Q_{\mathrm{p}}$ & $2 a, c$ & & [59] \\
\hline $\mathrm{Ni}-\mathrm{Zr}$ & m.s. & $\approx 20 \mu \mathrm{m}$ & $\Omega_{0}, Q_{\mathrm{p}}$ & $2 \mathrm{a}$ & & [60] \\
\hline $\mathrm{Ni}-\mathrm{Zr}$ & m.s. & $20-30 \mu \mathrm{m}$ & $T_{\mathrm{g}}, T_{\mathrm{X}}, H_{\mathrm{X}}, \rho$ & $2 \mathrm{~g}, \mathrm{i}, \mathrm{k}$ & & [61] \\
\hline $\mathrm{Ni}-\mathrm{Zr}$ & m.s. & $25-35 \mu \mathrm{m}$ & $\Omega_{0}, Q_{\mathrm{p}}$ & $2 a, c$ & & [62] \\
\hline $\mathrm{Ni}-\mathrm{Zr}$ & m.s. & N/A & $Q_{\mathrm{p}}, T_{\mathrm{g}}, T_{\mathrm{X}}$ & $2 \mathrm{c}, \mathrm{g}$ & & [63] \\
\hline $\mathrm{Ni}-\mathrm{Zr}$ & m.s. & N/A & $H_{\mathrm{X}}$ & $2 \mathrm{i}$ & & [64] \\
\hline $\mathrm{Ni}-\mathrm{Zr}$ & m.s. & N/A & $Q_{\mathrm{p}}$ & $2 \mathrm{c}$ & $\diamond$ & [65] \\
\hline $\mathrm{Ni}-\mathrm{Zr}$ & b.m. & - & $Q_{\mathrm{p}}$ & $2 c$ & & [66] \\
\hline $\mathrm{Ni}-\mathrm{Zr}$ & b.m. & - & $Q_{\mathrm{p}}, T_{\mathrm{X}}$ & $2 \mathrm{c}, \mathrm{g}$ & $\ominus$ & [67] \\
\hline $\mathrm{Ni}-\mathrm{Zr}$ & d.c. & - & $N\left(E_{\mathrm{F}}\right)$ & $2 \mathrm{e}$ & & [68] \\
\hline $\mathrm{Ni}-\mathrm{Zr}$ & d.c. & - & $T_{\mathrm{g}}$ & $2 \mathrm{~g}$ & $\rightarrow$ & [69] \\
\hline $\mathrm{Ni}-\mathrm{Zr}$ & m.s. & N/A & $\Omega_{0}$ & $2 \mathrm{a}$ & $\Delta$ & [70] \\
\hline $\mathrm{Ni}-\mathrm{Zr}$ & m.s. & N/A & $Q_{\mathrm{p}}$ & $2 \mathrm{c}$ & $\boldsymbol{\Delta}$ & [71] \\
\hline $\mathrm{Ni}-\mathrm{Zr}$ & s.d. & $800 \mathrm{~nm}$ & $Q_{\mathrm{p}}$ & $2 \mathrm{c}$ & 0 & [72] \\
\hline $\mathrm{Ni}-\mathrm{Zr}$ & a.m. & $\approx 2.5 \mathrm{~mm}$ & $Q_{\mathrm{p}}, T_{\mathrm{X}}$ & $2 \mathrm{c}, \mathrm{g}$ & $\star$ & [73] \\
\hline $\mathrm{Ni}-\mathrm{Zr}$ & s.d. & $500 \mathrm{~nm}$ & $Q_{\mathrm{p}}$ & $2 \mathrm{c}$ & $\diamond$ & [74] \\
\hline $\mathrm{Ni}-\mathrm{Zr}$ & s.d. & $4-6 \mu \mathrm{m}$ & $\Omega_{0}$ & $2 a$ & $\square$ & [75] \\
\hline $\mathrm{Cu}-\mathrm{Zr}$ & m.s. & $\approx 20 \mu \mathrm{m}$ & $\Omega_{0}, T_{\mathrm{X}}, H_{\mathrm{X}}, \rho$ & 2b,h,j,1 & 0 & [76] \\
\hline $\mathrm{Cu}-\mathrm{Zr}$ & m.s. & $\approx 20 \mu \mathrm{m}$ & $\Omega_{0}, \rho$ & $2 b, 1$ & & [60] \\
\hline $\mathrm{Cu}-\mathrm{Zr}$ & m.s. & N/A & $Q_{\mathrm{p}}$ & $2 d$ & - & [77] \\
\hline $\mathrm{Cu}-\mathrm{Zr}$ & m.s. & N/A & $Q_{\mathrm{p}}, T_{\mathrm{X}}$ & $2 \mathrm{~d}, \mathrm{~h}$ & & [63] \\
\hline $\mathrm{Cu}-\mathrm{Zr}$ & m.s. & N/A & $\rho$ & 21 & & [78] \\
\hline $\mathrm{Cu}-\mathrm{Zr}$ & c.a. & $2 \mu \mathrm{m}$ & $Q_{\mathrm{p}}$ & $2 \mathrm{~d}$ & & [79] \\
\hline $\mathrm{Cu}-\mathrm{Zr}$ & d.c. & - & $N\left(E_{\mathrm{F}}\right)$ & $2 \mathrm{f}$ & & [68] \\
\hline $\mathrm{Cu}-\mathrm{Zr}$ & d.c. & - & $T_{\mathrm{g}}$ & $2 \mathrm{~h}$ & $>$ & [69] \\
\hline $\mathrm{Cu}-\mathrm{Zr}$ & m.s. & N/A & $\Omega_{0}^{\circ}$ & $2 b$ & $\Delta$ & [70] \\
\hline $\mathrm{Cu}-\mathrm{Zr}$ & m.s. & $25 \mu \mathrm{m}$ & $\Omega_{0}, T_{\mathrm{g}}, T_{\mathrm{X}}$ & $2 b, h$ & $\mathbf{v}$ & [80] \\
\hline $\mathrm{Cu}-\mathrm{Zr}$ & s.d. & $\approx 128 \mathrm{~nm}$ & $\Omega_{0}$ & $2 b$ & $\square$ & [81] \\
\hline $\mathrm{Cu}-\mathrm{Zr}$ & m.s. & $25 \mu \mathrm{m}$ & $Q_{\mathrm{p}}, T_{\mathrm{g}}, T_{\mathrm{X}}$ & $2 \mathrm{~d}, \mathrm{~h}$ & 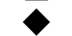 & [82] \\
\hline $\mathrm{Cu}-\mathrm{Zr}$ & i.c. & $2 \mathrm{~mm}$ & $T_{\mathrm{g}}, \stackrel{\leftrightarrow}{T}_{\mathrm{X}}$ & $2 \mathrm{~h}$ & & [83] \\
\hline $\mathrm{Cu}-\mathrm{Zr}$ & m.s. & N/A & $\Omega_{0}, Q_{\mathrm{p}}$ & $2 b, d$ & 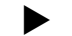 & [84] \\
\hline $\mathrm{Cu}-\mathrm{Zr}$ & m.s. & $\approx 2 \mathrm{~mm}$ & $Q_{\mathrm{p}}$ & $2 d$ & $\nabla$ & [85] \\
\hline $\mathrm{Cu}-\mathrm{Zr}$ & m.s. & N/A & $Q_{\mathrm{p}}$ & $2 \mathrm{~d}$ & $\Delta$ & [86] \\
\hline $\mathrm{Cu}-\mathrm{Zr}$ & a.m. & $\approx 2.5 \mathrm{~mm}$ & $Q_{\mathrm{p}}$ & $2 \mathrm{~d}$ & $\star$ & [87] \\
\hline $\mathrm{Cu}-\mathrm{Zr}$ & s.d. & $4-6 \mu \mathrm{m}$ & $\Omega_{0}$ & $2 \mathrm{~b}$ & $\square$ & [75] \\
\hline
\end{tabular}

Table 2: Preparation method (f.e.: flash evaporation[88], m.s.: melt spinning, b.m.: ball milling, d.c.: results are obtained from a data collection, a.m.: arcmelting (i.e. arc-melted samples used directly), i.c.: injection casting) and thickness (where appropriate) of the binary alloys considered in this study together with the physical quantities used, the figures in which they are plotted, the respective symbols (open (thin films), half open (mechanical alloying), closed (preparation from the melt and bulk samples)) used in the figures and the literature reference.

assumption, at least in the c-case, is not fulfilled over the complete concentration range and reduced values, i.e. higher packing densities, were observed[71, 89]. For $\bar{Z}$ in Eq. (1) different assumptions were used as discussed in the following. While, as explained in the introduction, for all the $\mathrm{TM} Z_{\mathrm{TM}}=1.5$

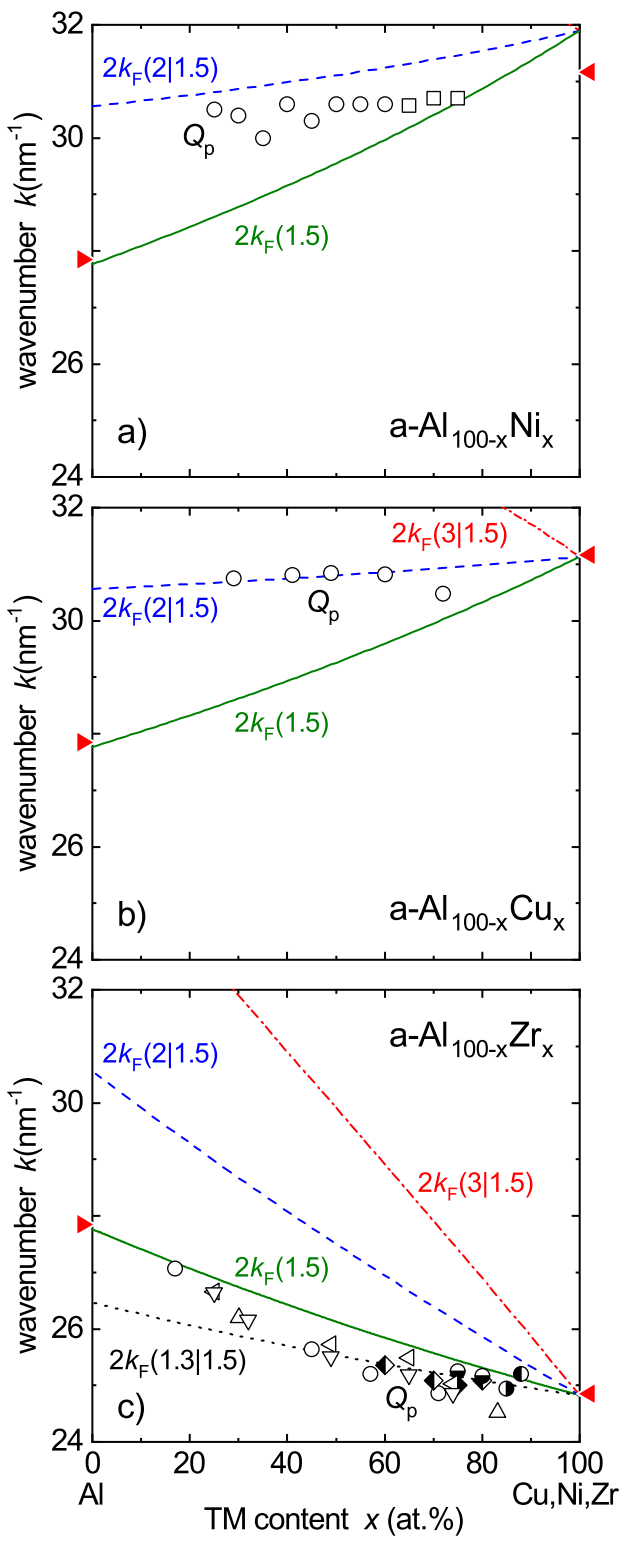

Figure 1: Positions of the principal peak $Q_{\mathrm{p}}$ in $S(Q)$ of a) binary a-Al-Ni, b) binary a-Al-Cu and c) binary a-Al-Zr alloys versus the concentration $x$ of the respective TM element. Table 2 serves as legend for the symbols. The solid lines represent $2 k_{\mathrm{F}}$ calculated using Eq. (1) for different valences as denoted at the curves. The red triangles indicate $Q_{\mathrm{p}, \text { at }}$ for the pure elements estimated from the atomic radii $r_{\text {at }}$ via Eq. (4) (see text). (For interpretation of the references to colour the reader is referred to the web version of this article.)

was assumed for $\mathrm{Al}$ different values were taken into consideration: using $Z_{\mathrm{Al}}=3$, as is to be expected from the position of $\mathrm{Al}$ in the periodic table, Eq. (1) delivers values of $2 k_{\mathrm{F}}$, denoted by $2 k_{\mathrm{F}}(3 \mid 1.5)$ (red dash-dotted lines in Fig. 1), that can in no case describe the measured $Q_{\mathrm{p}}$. It has been proposed that Al can exhibit an effective valence of 2 owing to the aforementioned hybridisation effects in a-Al-TM alloys[90] $\left(2 k_{\mathrm{F}}(2 \mid 1.5)\right.$, blue dashed lines in Fig. 1). This provides indeed a reasonable assumption for a-Al-(Ni,Cu). For a-Al-Zr, especially for low $\mathrm{Zr}$-content, however, $Z_{\mathrm{Al}}=1.5$, like for the TM, is more appropriate $\left(2 k_{\mathrm{F}}(1.5)\right.$, green solid line Fig. $\left.1 \mathrm{c}\right)$. For higher $\mathrm{Zr}$-content 
a deviation towards even lower values of $Z_{\mathrm{Al}}$ seems to take place as illustrated by the black dotted curve in Fig. 1c which is calculated assuming $Z_{\mathrm{Al}}=1.3$, i.e. $2 k_{\mathrm{F}}(1.3 \mid 1.5)$. Altogether, it appears that depending on the TM, especially if it as an early or a late TM, the alloys exhibit different structural behaviour, reflected in an unusual variability of $Z_{\mathrm{Al}}$. This, with special attention being paid to the behaviour for $x \lesssim 20$, shall be addressed in more detail in a future publication by additionally considering further a-Al-TM-systems. From the considerations above an interval $1.3 \leq Z_{\mathrm{Al}} \leq 2$ can be assumed which has to be taken into account when the role of $\mathrm{Al}$ in multinary alloys has to be evaluated.

The red triangles in Fig. 1 point to estimated values of $Q_{\mathrm{p}}$ for the pure components in their hypothetical a-state assuming that the nearest-neighbour distance $r_{0}$ (Eq. (2) with $n=0$ ) is determined by their respective atomic radius $r_{\text {at }}$ (Tab. 1), i.e. $r_{0}=2 r_{\text {at }}$, which gives

$$
Q_{\mathrm{p}, \mathrm{at}}=\frac{5}{4} \cdot \frac{2 \pi}{r_{0}}=\frac{5}{4} \cdot \frac{2 \pi}{2 r_{\mathrm{at}}}=\frac{5}{4} \cdot \frac{\pi}{r_{\mathrm{at}}} .
$$

Regarding an extrapolation of the experimental results for $Q_{\mathrm{p}}$ shown in Fig. 1 this indeed seems to be a good assumption for pure $\mathrm{Cu}, \mathrm{Ni}$ and $\mathrm{Zr}$. For $\mathrm{Al}$, however, only in the case of a-Al- $\mathrm{Zr}$ a good agreement can be found, highlighting again the possible variable behaviour of $\mathrm{Al}$ depending on the alloying element. It is interesting to note that $Q_{\mathrm{p} \text {,at }}$ for $\mathrm{Al}, \mathrm{Ni}, \mathrm{Cu}$ and $\mathrm{Zr}$ is always close to their respective $2 k_{\mathrm{F}}(1.5)$ (Fig. 1).

\subsection{Binary $\mathrm{a}-\mathrm{Zr}-(\mathrm{Ni}, \mathrm{Cu})$ alloys}

In this section we discuss the relation between $2 k_{\mathrm{F}}$ and $Q_{\mathrm{p}}$ for a-Zr- $(\mathrm{Ni}, \mathrm{Cu})$ alloys and its reflexion in several other properties of these alloys (Fig. 2). Again we use a valence of 1.5 for $\mathrm{Zr}$ as well as $\mathrm{Ni}$ and $\mathrm{Cu}$, i.e. the valence is assumed to stay constant at 1.5 over the complete concentration range. The change of $2 k_{\mathrm{F}}$ therefore only depends on the change of the mean atomic volume $\Omega_{0}$ which is again calculated as concentration-weighted average (solid black lines in Fig. 2a,b) over the values for the pure elements (Tab. 1). Compared with experimental results this seems to be a very good approximation over the complete known concentration range for a-Zr-Cu (Fig. 2b) and is seen as an indication for ideal-solution behaviour[91-93]. For a-Zr-Ni, however, a deviation to smaller volumes, i.e. higher packing densities, in the range $40 \leq x_{\mathrm{Ni}} \leq 80$ can be seen (dash-dotted black line in Fig. 2a). This behaviour has been observed before and was ascribed to strong local chemical interactions as hinted by the high negative $\Delta H_{\mathrm{Ni}-\mathrm{Zr}}^{\mathrm{mix}}$ (Tab. 1)[71, 94].

The calculated $2 k_{\mathrm{F}}$ are plotted in Fig. $2 \mathrm{c}$,d over the complete concentration range using the atomic volumes according to the ideal-solution behaviour (solid green lines). For a-Zr-Ni additionally the deviation from ideal-solution behaviour is taken into account which results in an increase of $2 k_{\mathrm{F}}$ especially for high Ni-content (dash-dotted green line in Fig. 2c). The close proximity of $Q_{\mathrm{p} \text {,at }}$ (red triangles in Fig. 2c,d) calculated via Eq. (4) and $2 k_{\mathrm{F}}(1.5)$ for the pure elements is already an indication that global and local effects might act hand in hand. For both systems the measured $Q_{\mathrm{p}}$ are close to $2 k_{\mathrm{F}}(1.5)$ also over the com- plete concentration ranges but $Q_{\mathrm{p}}<2 k_{\mathrm{F}}(1.5)$ for $x_{\mathrm{Ni}}<55$ and $x_{\mathrm{Cu}}<50$, respectively (Fig. $2 \mathrm{c}, \mathrm{d}$ ).

While for a-Zr-Ni a distinct S-shaped dependence of $Q_{\mathrm{p}}$ versus $x_{\mathrm{Ni}}$ is obvious this behaviour is much less pronounced or virtually absent for a-Zr-Cu. It can be seen that both systems behave very similar, again, up to around $x \approx 55$. For a better comparison the composition dependence of $Q_{\mathrm{p}}$ for the respective other system is drawn as thick grey lines in Fig. 2c,d. In a-Zr-Cu for $x_{\mathrm{Cu}} \gtrsim 50$ up to virtually the highest measured $x_{\mathrm{Cu}}$ an almost perfect agreement of $Q_{\mathrm{p}}$ and $2 k_{\mathrm{F}}(1.5)$ becomes obvious. For a-Zr-Ni this agreement (dash-dotted green line) can only be found in the range $55 \lesssim x_{\mathrm{Ni}} \lesssim 70$.

The good agreement of $Q_{\mathrm{p}}$ and $2 k_{\mathrm{F}}(1.5)$, especially that $Q_{\mathrm{p}}$ follows the "hump" in $2 k_{\mathrm{F}}$ for a-Zr-Ni, can be regarded as strong indication for the influence of a global resonance as outlined in the introduction. The concentration ranges with perfect agreement, i.e. $Q_{\mathrm{p}}=2 k_{\mathrm{F}}$, are highlighted by vertical dashed lines in Fig. 2c,d as well as in the remainder of Fig. 2.

That $Q_{\mathrm{p}}$ and $2 k_{\mathrm{F}}(1.5)$ do not coincide over the complete concentration range suggests that further effects are active. Those can be seen in constraints on the local scale that have to be fulfilled as well. It can be assumed that none of the effects alone is able to explain the structural behaviour completely. Only if both local and global needs are satisfied the most favourable structure can emerge. Global (resonance) and local effects (CSRO) might support each other or are even mutually dependent on each other to achieve the most favourable situation for the alloy. It might furthermore be argued that an $E_{\mathrm{F}}$ not optimally located in the center of a pseudogap can be counterbalanced by local effects, e.g. local covalent bonding, i.e. strong local chemical interactions. The system can then be in a favourable state even if $Q_{\mathrm{p}}$ and $2 k_{\mathrm{F}}$ do not coincide, as is observed in a- $\mathrm{Zr}$-(Ni, $\left.\mathrm{Cu}\right)$ for $x_{\mathrm{Ni}} \lesssim 55$ and $x_{\mathrm{Cu}} \lesssim 50$, respectively (Fig. 2c,d). Altogether this helps to understand the good GFA in a-Zr-(Ni,Cu) which, particularly for a- $\mathrm{Zr}-\mathrm{Cu}$, was found unexpectedly less dependent on factors like the occurrence of eutectics or intermetallic phases[95-99]. A deeper analysis of the intricate interplay between local and global effects might also be able to explain finer details like the oscillating GFA observed in a- $\mathrm{Zr}-\mathrm{Cu}$ for $48 \leq x_{\mathrm{Cu}} \leq 69$ [81]. Below $x_{\mathrm{Ni}} \approx 55$ and $x_{\mathrm{Cu}} \approx 50$ global effects seem to be less important since for both systems $Q_{\mathrm{p}}<2 k_{\mathrm{F}}$. Furthermore, $Q_{\mathrm{p}}$ behaves virtually identical for both systems (cf. grey lines in Fig. 2c,d) although the slope of $2 k_{\mathrm{F}}(1.5)$ for a-Zr-Ni is different than that for a- $\mathrm{Zr}-\mathrm{Cu}$. In this concentration region $Q_{\mathrm{p}}$ and $2 k_{\mathrm{F}}$ seem to be decoupled. The achievement of resonance accomplishes a smaller energy gain then optimising the local constraints, i.e. local effects are improved at the expense of those on the global scale. Additionally, it would be interesting to see how $Q_{\mathrm{p}}$ approaches the respective $Q_{\mathrm{p} \text {,at }}$ for the pure elements in their hypothetical a-state for which the dashed red lines in Fig. 2c,d may serve as a prediction.

For a further discussion the knowledge of experimentally obtained DOS spectra over a wide concentration range with small steps in $x_{\mathrm{Ni}, \mathrm{Cu}}$ would be necessary to monitor composition dependent changes in detail. Currently available PES or IPES results cover only a few compositions[100-106]. Theoretical investigations, on the other hand, cover a somewhat wider com- 

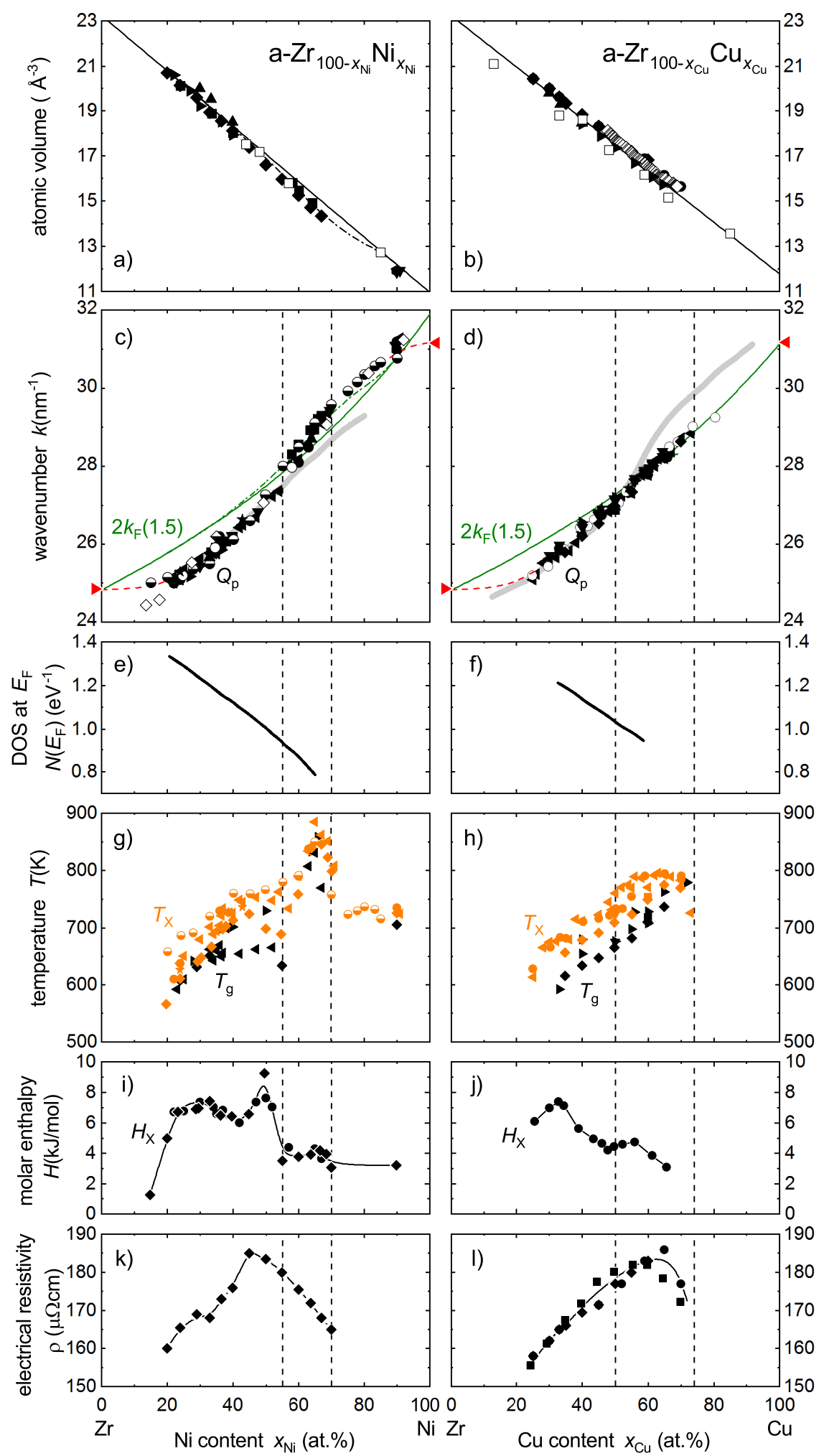

Figure 2: Comparison of a-Zr-Ni (left column) and a-Zr-Cu (right column) alloys. Table 2 serves as legend for the symbols. From top to bottom: a,b) atomic volume $\Omega_{0} ; \mathrm{c}, \mathrm{d}$ ) position $Q_{\mathrm{p}}$ of the first maximum in $S(Q)$; e,f) density of states at the Fermi level $N\left(E_{\mathrm{F}}\right.$ ); g,h) glass transition temperature $T_{\mathrm{g}}$ (black) and crystallisation temperature $T_{\mathrm{X}}$ (orange); i,j) enthalpy of crystallisation $\left.H_{\mathrm{X}} ; \mathrm{k}, 1\right)$ electrical resistivity $\rho$ versus the concentration $x_{\mathrm{Ni}, \mathrm{Cu}}$ of the alloying element $(\mathrm{Ni}, \mathrm{Cu})$. The additional lines mean in a,b) assumption of constant atomic volumes $\Omega_{0}$ during alloying (solid black) and fit to the deviation from this behaviour (dash-dotted black); $\mathrm{c}, \mathrm{d}$ ) $2 k_{\mathrm{F}}$ calculated with Eq. (1) using $\bar{Z}=1.5$ (solid green) and taking into account the decreased atomic volume (dash-dotted green) as well as the estimated continuation towards the pure elements (dashed red), the average composition dependence of $Q_{\mathrm{p}}$ for the respective other system (thick solid grey); i,j,k,l) guides for the eye. The vertical dashed lines in c,d,e,f,g,h,i,j,k,l) limit the concentration regions were $Q_{\mathrm{p}}=2 k_{\mathrm{F}}$ is fulfilled. The red triangles in c,d) indicate $Q_{\mathrm{p}, \text { at }}$ of the elements estimated from the atomic radii $r_{\text {at }}$ using Eq. (4) (see text). (For interpretation of the references to colour the reader is referred to the web version of this article.) 
position region[36, 37], but their interpretation is controversial, ranging from a "lack of DOS minimum at the Fermi level"[37] to "always a pseudogap in the density of state at the Fermi level" [36] for virtually the same $\mathrm{Cu}$-content. It is, however, possible to discuss at least the DOS at the Fermi level, $N\left(E_{\mathrm{F}}\right)$, over a relatively wide concentration range. Those values can indirectly be obtained by measurements of the magnetic susceptibility, low temperature specific heat and superconducting properties $[60,68$, 107]. Such results are shown in Fig. 2e,f[68]. For both systems a monotonic an almost linear decrease of $N\left(E_{\mathrm{F}}\right)$ with decreasing difference between $Q_{\mathrm{p}}$ and $2 k_{\mathrm{F}}$ is visible whereby for a-Zr-Ni the modulus of the slope even increases in the region where $Q_{\mathrm{p}}=2 k_{\mathrm{F}}$. This indeed hints the energetic advantage as expected from a system under resonance. Future measurements have to show how $N\left(E_{\mathrm{F}}\right)$ behaves for higher $x_{\mathrm{Ni}, \mathrm{Cu}}$.

To verify whether the agreement $Q_{\mathrm{p}}=2 k_{\mathrm{F}}$ is indeed reflected in a higher thermal stability of the a-phase Fig. $2 \mathrm{~g}$, h shows the crystallisation temperatures $T_{\mathrm{X}}$ (orange) of the alloys and furthermore the glass transition temperatures $T_{\mathrm{g}}$ (black). Figure $2 \mathrm{i}$,j shows $H_{\mathrm{X}}$, the molar enthalpy of crystallisation. In the concentration region where $Q_{\mathrm{p}}=2 k_{\mathrm{F}}$ for a-Zr-Ni a peak in $T_{\mathrm{X}}$ accompanied by a considerable drop of $H_{\mathrm{X}}$ is obvious. At the same time $T_{\mathrm{g}}$ also shows a maximum. A similar behaviour can be observed in a-Zr-Cu. This provides further evidence for the influence of global stabilisation effects as expected for systems under resonance.

Since electronic transport properties are inherently dependent on the electronic structure at $E_{\mathrm{F}}$ they can give further information on the resonance. Therefore, in the last row of Fig. 2 the electric resistivity $\rho$ of a-Zr- $(\mathrm{Ni}, \mathrm{Cu})$ versus $x_{\mathrm{Ni}, \mathrm{Cu}}$ is shown. For a-systems Faber-Ziman-like theories are often used to directly connect $S(Q)$ with $\rho$ [108-110]. Thereafter high $\rho$ are expected if the resonance condition $Q_{\mathrm{p}}=2 k_{\mathrm{F}}$ is fulfilled. While for a-Zr$\mathrm{Cu}$ this indeed seems to be the case (Fig. 2l) the maximal $\rho$ for a-Zr-Ni occurs a few at.\% below which reflects the more complicated behaviour when d-states at $E_{\mathrm{F}}$ are involved (e.g. Mott s-d-scattering $[109,111,112])$. In addition to the properties presented in Fig. 2 it is known that a- $\mathrm{Zr}-\mathrm{Cu}$ exhibits extrema for further material parameters in the concentration region around $x_{\mathrm{Cu}}=65$ for instance a minimum of the plastic strain and maxima of Young's modulus and yield strength[113].

To get an impression of the resonance effects in $r$-space Fig. 3 shows the structure factors $S(Q)$ (left) and pair correlation functions $g(r)$ (right) of a-Zr-Cu for $x_{\mathrm{Cu}}=33,50,60$. The green vertical bars at the curves indicate in Fig. $3 \mathrm{a} 2 k_{\mathrm{F}}(1.5)$ and in Fig. $3 b$ the shell distances according to the SPO (Eq. (3)). A good agreement both in $k$ - and $r$-space can be seen. In $r$-space, however, there are structural features, like the split first peak, that cannot be explained by the SPO in its current form. A possible way of including such effects of chemical order in a refined future form is provided by the scattering interpretation of the SPO as outlined in the introduction, taking into account the different scattering properties of the individual species for the valence electrons. Moreover, it is known from binary and ternary a-Al-TM alloys that act as precursors for quasicrystals that they show an additional sequence in $g(r)$ which is correlated with the Golden ratio $\tau \approx 1.618$ indicating icosahedral
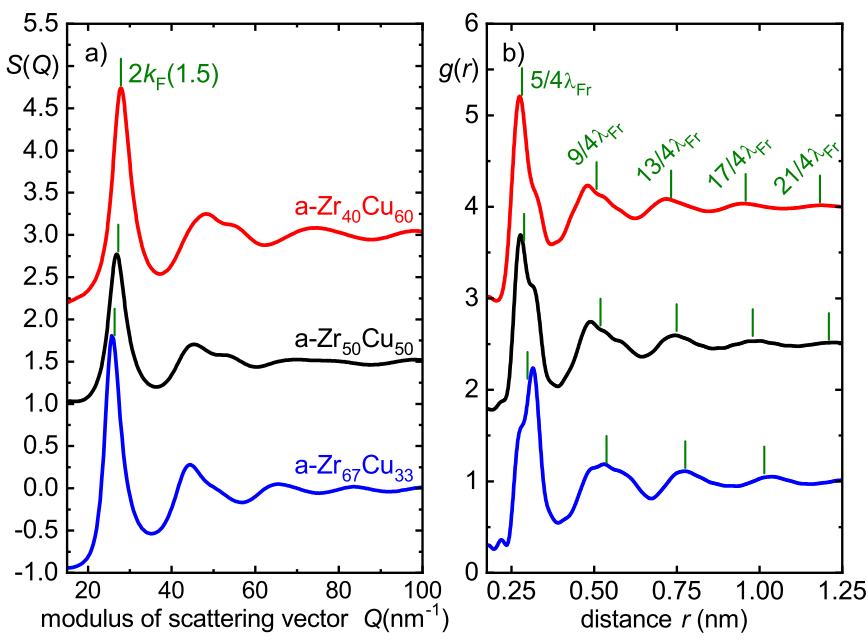

Figure 3: a) structure factors $S(Q)$ and b) pair correlation functions $g(r)$ of three a-Zr-Cu alloys[92]. The curves are shifted along the $y$-axes for better clarity. The green vertical bars indicate in a) the positions of $2 k_{\mathrm{F}}(1.5)$ (Eq. (1)) and in b) the radii of the coordination shells according to the SPO (Eq. (3)) calculated using $\bar{Z}=1.5$. (For interpretation of the references to colour the reader is referred to the web version of this article.)

order[114, 115]. A more detailed analysis for a-Zr-Cu alloys, especially in the composition region where $Q_{\mathrm{p}}=2 k_{\mathrm{F}}$ is fulfilled, has to show whether this is also the case here, since icosahedral order plays a major role in this system as well[116, 117]. At least in molecular-dynamics simulations it was found that in this very composition region the icosahedron is the dominant short-range structure[113, 118].

\section{Ternary alloys}

It is well-known that the addition of $\mathrm{Al}$ to $\mathrm{a}-\mathrm{Zr}-(\mathrm{Ni}, \mathrm{Cu}) \mathrm{im}-$ proves their GFA greatly which was discussed mainly, again, on a local basis taking into account the high negative values of $\Delta H_{\mathrm{Al}-B}^{\mathrm{mix}}$ (Tab. 1) causing deviations from the ideal-solution behaviour and leading to an increased CSRO[71, 92, 119-123]. Strong covalent-like directional bonding of $\mathrm{Al}$ with the other species in the alloy as a result of hybridisation was identified as an important driving force in shortening interatomic distances which results in an enhanced cohesion of clusters[123, 124]. Global effects, on the other hand, can be discussed here as well in the same manner as done for the binary systems in the previous sections if straight lines in the ternary phase diagrams are chosen.

In this section we will briefly discuss only one of such lines each for the ternary systems a-Zr-Ni-Al and a-Zr-Cu-Al, respectively. Figure 4 shows $Q_{\mathrm{p}}$ for a- $\left(\mathrm{Zr}_{64} \mathrm{Ni}_{36}\right)_{100-x} \mathrm{Al}_{x}$ (for $x=$ $0,5,10,15,20,25$ from [125]) and $\mathrm{a}-\mathrm{Zr}_{50} \mathrm{Cu}_{50-x} \mathrm{Al}_{x}$ (for $x=$ $0,10,20,30$ from [92], for $x=50$ data for $\mathrm{a}-\mathrm{Al}_{51} \mathrm{Zr}_{49}$ from $[55,56]$ is used). Using Eq. (1) the green solid lines in Fig. 4 showing $2 k_{\mathrm{F}}(1.5|1.5| 1.3)$, i.e. assuming $Z=1.5$ for $\mathrm{Zr}, \mathrm{Ni}, \mathrm{Cu}$ and $Z=1.3$ for $\mathrm{Al}$, were calculated. The latter assumption is based on the results from Sec. 2.1 for high $\mathrm{Zr}$-content but has to be validated by more thorough studies in the future. 
For both systems a good agreement $Q_{\mathrm{p}} \approx 2 k_{\mathrm{F}}$ can be found. With increasing Al-content the distance between $Q_{\mathrm{p}}$ and $2 k_{\mathrm{F}}$ decreases in both cases which seems to be correlated with an increase of the crystallisation temperatures $T_{\mathrm{X}}$ (orange points and right $y$-axes in Fig. 4) indicating, again, the presence of resonance. To further investigate the influence of global effects
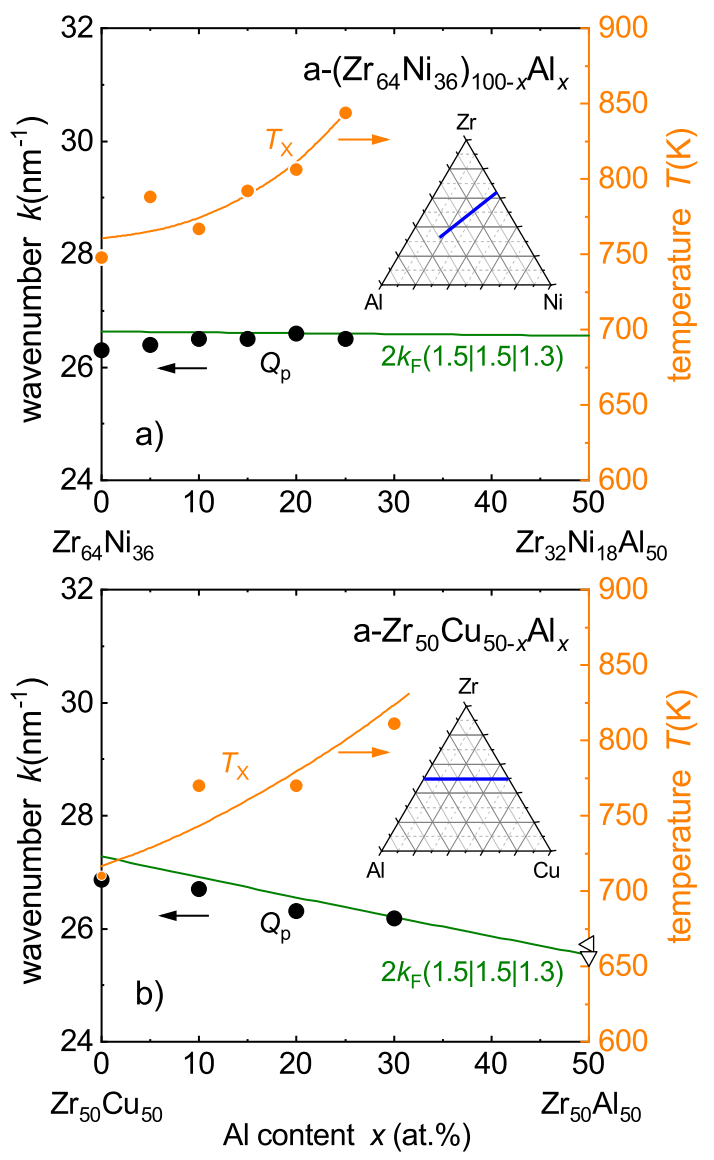

Figure 4: Positions of the principal peak $Q_{\mathrm{p}}$ in $S(Q)$ of the ternary alloys a) $\mathrm{a}-\left(\mathrm{Zr}_{64} \mathrm{Ni}_{36}\right)_{100-x} \mathrm{Al}_{x}[125]$ and b) $\mathrm{a}-\mathrm{Zr}_{50} \mathrm{Cu}_{50-x} \mathrm{Al}_{x}$ [92] (for $x=50$ data for a$\mathrm{Al}_{51} \mathrm{Zr}_{49}$ from $[55,56]$ is used). The solid green lines represent $2 k_{\mathrm{F}}(1.5|1.5| 1.3)$ calculated using Eq. (1) with the given valences for $\mathrm{Zr},(\mathrm{Ni}, \mathrm{Cu})$ and $\mathrm{Al}$. The insets may serve as an orientation as to where the respective alloys are located in the ternary phase diagrams (blue lines). The orange points show $T_{\mathrm{X}}$ (right $y$-axes) $[92,125]$. The orange lines are guides for the eye. (For interpretation of the references to colour the reader is referred to the web version of this article.)

on the multinary systems and its correlation with other properties, a lot more experimental data has to be acquired. Especially the systematic study of the influence of Al-addition to a$\mathrm{Zr}-(\mathrm{Ni}, \mathrm{Cu})$ in the region of their highest stability, i.e. around 60 at.\% $(\mathrm{Ni}, \mathrm{Cu})$, would be desirable. It is, finally, worth noting that a pseudogap at $E_{\mathrm{F}}$ was found experimentally for one of the most important bulk metallic glasses, $\mathrm{a}-\mathrm{Zr}_{55} \mathrm{Ni}_{5} \mathrm{Cu}_{30} \mathrm{Al}_{10}$ [126], and was surmised to aid its large GFA[6].

\section{Conclusions}

The effect of global interactions on glass forming ability of binary $\mathrm{Zr}-\mathrm{Ni}$ and $\mathrm{Zr}-\mathrm{Cu}$ metallic glasses has been studied. For this the positions of the principal maximum $Q_{\mathrm{p}}$ in the static structure factors $S(Q)$ have been investigated in terms of their relation to the diameter of the Fermi sphere $2 k_{\mathrm{F}}$. A good agreement is found by taking into account a mean valence of $\bar{Z}=1.5$ over the complete concentration ranges. Furthermore $2 k_{\mathrm{F}}$ is close to a structure that is to be expected from local packing constraints due to the atomic radii of the components which can provide an explanation of the good glass forming ability over wide concentration regions in these systems. The structure can be considered as the result of a mutual arrangement of global and local effects. Correlations of the atomic structure, formed under these circumstances, with other properties of the alloys are pointed out. The spherical periodic order can explain the average positions of the maxima in the pair correlation function very well but has to be refined in the future to be able to account for the details due to the partial pair correlations. In order to get a more complete picture of the electronic structure a systematic synchrotron-based photo-electron spectroscopic study over wide concentration ranges supplemented by according inverse photo-electron spectroscopy has to be undertaken. Only the combination of PES and IPES can successfully reveal minima and trends in the DOS at $E_{\mathrm{F}}$ depending on the composition. Further valuable insights may arise from studies on a-Zr(Fe,Co) and a-(Hf,Ti)-(Fe,Co,Ni,Cu). Especially for a-(Hf,Ti)$(\mathrm{Ni}, \mathrm{Cu})$ similar behaviour can be expected as hinted by previous studies[68, 93, 107].

Using the insights obtained for the binary alloys as a basis trends in the structure of multinary systems can be understood, as shown exemplarily for a-Zr-(Ni,Cu)-Al. A more detailed comprehension, however, is currently hampered by the uncertainty in the valence of Al. Further studies have to clarify what determines this quantity.

\section{Acknowledgements}

We wish to thank Dr. J. Antonowicz, Prof. D.V. Louzguine, Dr. G. Vaughan, Prof. H. Solbrig and Prof. J.-G. Gasser for insightful discussions. The ESRF is acknowledged for the experimental support during synchrotron X-ray-diffraction at the beamlines ID11 and ID15. Financial support from the EPSRCDTP studentship "Bulk Metallic Glasses: Revealing the Structural Pathway of Liquid Metals to Vitrification" (project reference 2043971) within the framework of the EPSRC Doctoral Training Partnership with Cranfield University (EP/N509450/1) and from the EPSRC project "Energy Resilient Manufacturing: Small is Beautiful (Phase 2)" (EP/P012272/1) is gratefully acknowledged. In memory of Prof. A.R. Yavari.

\section{References}

[1] A. L. Greer. Metallic glasses...on the threshold. Mater. Today 12 (2009) 14. doi:10.1016/S1369-7021(09)70037-9.

[2] M. M. Khan, A. Nemati, Z. U. Rahman, U. H. Shah, H. Asgar, W. Haider. Recent Advancements in Bulk Metallic Glasses and Their Applications: A Review. Crit. Rev. Solid State Mater. Sci. 43 (2018) 233. doi: 10.1080/10408436.2017.1358149.

[3] P. Häussler. Interrelations between atomic and electronic structuresLiquid and amorphous metals as model systems. Phys. Rep. 222 (1992) 65. doi:10.1016/0370-1573(92)90018-U. 
[4] P. Häussler, J. Barzola-Quiquia, D. Hauschild, J. Rauchhaupt, M. Stiehler, M. Hackert. Spherical periodicity, a general feature of matter at its early stages of formation. In TMS Annu. Meet. (edited by T. B. Massalski, P. Turchi) (The Minerals, Metals and Materials Society, 2005). ISBN 0-87339-593-X, pp. 43-86.

[5] Y. M. Wang, J. B. Qiang, C. H. Wong, C. H. Shek, C. Dong. Composition rule of bulk metallic glasses and quasicrystals using electron concentration criterion. J. Mater. Res. 18 (2003) 642. doi: 10.1557/JMR.2003.0084.

[6] K. Soda, K. Shimba, S. Yagi, M. Kato, T. Takeuchi, U. Mizutani, T. Zhang, M. Hasegawa, A. Inoue, T. Ito, S. Kimura. Electronic structure of bulk metallic glass $\mathrm{Zr}_{55} \mathrm{Al}_{10} \mathrm{Cu}_{30} \mathrm{Ni}_{5}$. J. Electron Spectros. Relat. Phenomena 144-147 (2005) 585. doi:10.1016/j.elspec.2005.01.139.

[7] M. Stiehler, J. Rauchhaupt, U. Giegengack, P. Häussler. On modifications of the well-known Hume-Rothery rules: Amorphous alloys as model systems. J. Non. Cryst. Solids 353 (2007) 1886. doi: 10.1016/j.jnoncrysol.2007.01.052.

[8] H. B. Yu, W. H. Wang, H. Y. Bai. An electronic structure perspective on glass-forming ability in metallic glasses. Appl. Phys. Lett. 96 (2010). doi:10.1063/1.3327337.

[9] W. Jiao, D. Zhao, D. Ding, H. Bai, W. Wang. Effect of free electron concentration on glass-forming ability of Ca-Mg-Cu system. J. Non. Cryst. Solids 358 (2012) 711. doi:10.1016/j.jnoncrysol.2011.10.033.

[10] C. C. Yuan, X. Shen, J. Cui, L. Gu, R. C. Yu, X. K. Xi. Atomic and electronic structures of $\mathrm{Zr}-(\mathrm{Co}, \mathrm{Ni}, \mathrm{Cu})$-Al metallic glasses. Appl. Phys. Lett. 101 (2012) 1. doi:10.1063/1.4734390.

[11] N. C. Wu, L. Zuo, J. Q. Wang, E. Ma. Designing aluminum-rich bulk metallic glasses via electronic-structure-guided microalloying. Acta Mater. 108 (2016) 143. doi:10.1016/j.actamat.2016.02.012.

[12] W. Hume-Rothery. Researches on the Nature, Properties, and Conditions of Formation of Intermetallic Compounds, with Special Reference to Certain Compounds of Tin. J. Inst. Met. 35 (1926) 295.

[13] H. Jones. The phase boundaries in binary alloys, part 2: the theory of the $\alpha, \beta$ phase boundaries. Proc. Phys. Soc. 49 (1937) 250. doi: 10.1088/0959-5309/49/3/307.

[14] A. T. Paxton, M. Methfessel, D. G. Pettifor. A bandstructure view of the Hume-Rothery electron phases. Proc. R. Soc. A Math. Phys. Eng. Sci. 453 (1997) 1493. doi:10.1098/rspa.1997.0080.

[15] U. Mizutani, H. Sato. The Physics of the Hume-Rothery Electron Concentration Rule. Crystals 7 (2017) 9. doi:10.3390/cryst7010009.

[16] P. Ossi, D. Kothari. Quasicrystals: an electron phase. J. Less Common Met. 171 (1991) 221. doi:10.1016/0022-5088(91)90145-T.

[17] J. Feng, N. W. Ashcroft, R. Hoffmann. Theoretical indications of singular structural and electronic features of laves-hase CaLi $i_{2}$ under pressure. Phys. Rev. Lett. 98 (2007) 1. doi:10.1103/PhysRevLett.98.247002.

[18] J. Feng, R. Hoffmann, N. W. Ashcroft. Double-diamond NaAl via pressure: Understanding structure through Jones zone activation. J. Chem. Phys. 132 (2010). doi:10.1063/1.3328198.

[19] U. Mizutani, H. Sato, M. Inukai, E. S. Zijlstra. Theoretical foundation for the hume-rothery electron concentration rule for structurally complex alloys. Acta Phys. Pol. A 126 (2014) 531. doi: 10.12693/APhysPolA.126.531.

[20] U. Mizutani, H. Sato. Energy gap formation mechanism through the interference phenomena of electrons in face-centered cubic elements and compounds with the emphasis on half-Heusler and Heusler compounds. Philos. Mag. 98 (2018) 1307. doi:10.1080/14786435.2018.1428772.

[21] M. Calvo-Dahlborg, S. G. Brown. Hume-Rothery for HEA classification and self-organizing map for phases and properties prediction. J. Alloys Compd. 724 (2017) 353. doi:10.1016/j.jallcom.2017.07.074.

[22] V. Degtyareva. Transformations of Phosphorus under pressure from simple cubic to simple hexagonal structures via incommensurately modulations: electronic origin. In Proc. 1st Int. Electron. Conf. Cryst., May (MDPI, Basel, Switzerland, 2018), p. 5243. doi:10.3390/IECC_201805243.

[23] S. R. Nagel, J. Tauc. Nearly-Free-Electron Approach to the Theory of Metallic Glass Alloys. Phys. Rev. Lett. 35 (1975) 380. doi: 10.1103/PhysRevLett.35.380.

[24] N. W. Ashcroft, N. D. Mermin. Solid State Physics (Saunders, 1976). ISBN 9780030839931

[25] P. Häussler. Analogies and differences between the crystalline and the disordered state. Phys. Status Solidi C Conf. 1 (2004) 2879. doi:
$10.1002 / \mathrm{pssc} .200405400$.

[26] P. Häussler, J. Barzola-Quiquia, M. Stiehler, J. Rauchhaupt, U. Giegengack, D. Hauschild, S. Neubert. On the formation of structure and electronic transport. J. Phys. Chem. Solids 68 (2007) 753 . doi: 10.1016/j.jpcs.2007.03.009.

[27] H. Nowak, P. Häussler. Concept of resonances in disordered metallic matter. J. Non. Cryst. Solids 250 (1999) 389. doi:10.1016/S00223093(99)00269-0.

[28] M. Lang, G. Schwalbe, C. Madel, R. Haberkern, P. Häussler. Variable Fe-valence as an effect of angular correlations? Ferroelectrics 250 (2001) 257. doi:10.1080/00150190108225077.

[29] J. Barzola-Quiquia, M. Lang, D. Decker, P. Häussler. Resonance stabilization triggered by hybridization effects. J. Non. Cryst. Solids 334-335 (2004) 352. doi:10.1016/j.jnoncrysol.2003.12.001.

[30] G. Trambly de Laissardière, D. Nguyen-Manh, D. Mayou. Electronic structure of complex Hume-Rothery phases and quasicrystals in transition metal aluminides. Prog. Mater. Sci. 50 (2005) 679. doi: 10.1016/j.pmatsci.2005.01.001.

[31] N. Wu, J. Lian, R. Wang, R. Li, W. Liu. Effect of element types on the glass forming ability of Al-TM-RE ternary metallic glasses using electron structure guiding. J. Alloys Compd. 723 (2017) 123. doi: 10.1016/j.jallcom.2017.06.262.

[32] D. G. Pettifor. Theory of energy bands and related properties of 4d transition metals. I. Band parameters and their volume dependence. J. Phys. F Met. Phys. 7 (1977) 613. doi:10.1088/0305-4608/7/4/013.

[33] J. A. Moriarty. Density-functional formulation of the generalized pseudopotential theory. II. Phys. Rev. B 26 (1982) 1754. doi: 10.1103/PhysRevB.26.1754.

[34] J. M. Wills, W. A. Harrison. Interionic interactions in transition metals. Phys. Rev. B 28 (1983) 4363. doi:10.1103/PhysRevB.28.4363.

[35] M. Weinert, R. E. Watson. Hybridization-induced band gaps in transition-metal aluminides. Phys. Rev. B 58 (1998) 9732. doi: 10.1103/PhysRevB.58.9732.

[36] H. Tian, Y. Liao, C. Zhang, J. Zhao, B. Wen, Q. Wang, C. Dong. A firstprinciple study of the structural and electronic properties of amorphous $\mathrm{Cu}$-Zr alloys. Sci. China Physics, Mech. Astron. 54 (2011) 249. doi: 10.1007/s11433-010-4136-5.

[37] J. Antonowicz, A. Pietnoczka, K. Pȩkała, J. Latuch, G. A. Evangelakis. Local atomic order, electronic structure and electron transport properties of $\mathrm{Cu}$-Zr metallic glasses. J. Appl. Phys. 115 (2014). doi: 10.1063/1.4879903.

[38] H. Beck, R. Oberle. On the stability of metallic glasses. Rapidly Quenched Met. III 1 (1978) 416.

[39] R. Oberle, H. Beck. The influence of pair potentials on the structure of polyvalent liquid metals. Solid State Commun. 32 (1979) 959. doi: 10.1016/0038-1098(79)90806-8.

[40] J. Kroha, A. Huck, T. Kopp. Coulomb Interaction and Disorder at $q=2 k_{\mathrm{F}}:$ A Novel Instability of the Fermi Sea and Implications for Amorphous Alloys. Phys. Rev. Lett. 75 (1995) 4278. doi: 10.1103/PhysRevLett.75.4278.

[41] D. B. Miracle, D. V. Louzguine-Luzgin, L. V. Louzguina-Luzgina, A. Inoue. An assessment of binary metallic glasses: correlations between structure, glass forming ability and stability. Int. Mater. Rev. 55 (2010) 218. doi:10.1179/095066010X12646898728200.

[42] T. Totemeier, W. Gale (eds.). Smithells Metals Reference Book (Butterworth-Heinemann, Oxford, 2004). ISBN 0750675098.

[43] M. J. Winter, U. of Sheffield. WebElements: The Web's Periodic Table (1997).

[44] A. Takeuchi, A. Inoue. Classification of Bulk Metallic Glasses by Atomic Size Difference, Heat of Mixing and Period of Constituent Elements and Its Application to Characterization of the Main Alloying Element. Mater. Trans. 46 (2005) 2817. doi:10.2320/matertrans.46.2817.

[45] J. Barzola-Quiquia. Szenarien der Strukturbildung in $A l_{100-x} \ddot{U} M_{x}$ Legierungen und Halbleitern sowie Konsequenzen daraus für elektronischen Transport. Doctoral thesis, Chemnitz University of Technology, Germany (2003).

[46] D. Dainat. Untersuchung der Struktur und des spezifischen Widerstandes amorpher Al-Cr- und Al-Ni-Schichten. Diploma thesis, Chemnitz University of Technology, Germany (2008).

[47] A. Lambrecht, H. Leitz, J. Hasse. Superconducting amorphous Al-Cu films of high stability. Zeitschrift für Phys. B Condens. Matter 38 (1980) 
35. doi:10.1007/BF01321200.

[48] H. J. Fecht, G. Han, Z. Fu, W. L. Johnson. Metastable phase formation in the $\mathrm{Zr}$-Al binary system induced by mechanical alloying. J. Appl. Phys. 67 (1990) 1744. doi:10.1063/1.345624.

[49] H. Yoshioka, H. Habazaki, A. Kawashima, K. Asami, K. Hashimoto. Anodic polarization behaviour of sputter-deposited Al-Zr alloys in a neutral chloride-containing buffer solution. Electrochim. Acta 36 (1991) 1227. doi:10.1016/0013-4686(91)85113-L.

[50] J. K. Ho, K. L. Lin. The metastable Al-Zr alloy thin films prepared by alternate sputtering deposition. J. Appl. Phys. 75 (1994) 2434. doi: $10.1063 / 1.356267$

[51] E. Ma, M. Atzmon. Phase transformations induced by mechanical alloying in binary systems. Mater. Chem. Phys. 39 (1995) 249. doi: 10.1016/0254-0584(94)01446-N

[52] H. W. Sheng, K. Lu, E. Ma. Amorphization Of Zr-Al Under Mechanical Alloying At Different Temperatures: A Re-Entrant Melting Phenomenon. MRS Proc. 481 (1997) 433. doi:10.1557/PROC-481-433.

[53] H. W. Sheng, K. Lu, E. Ma. Amorphization of Zr-Al solid solutions under mechanical alloying at different temperatures. J. Appl. Phys. 85 (1999) 6400. doi:10.1063/1.370143.

[54] F. Juranyi. Lattice instability in supersaturated solid solutions. Doctoral thesis, Chemnitz University of Technology, Germany (2003).

[55] K. Weller, N. Zotov, Z. Wang, L. Jeurgens, E. Mittemeijer. Atomic structure, electronic structure and thermal stability of amorphous $A l_{x} Z r_{1-x}(0.26 \leq x \leq 0.75)$. J. Non. Cryst. Solids 427 (2015) 104. doi: 10.1016/j.jnoncrysol.2015.07.036.

[56] K. Weller, T. Suter, Z. Wang, L. Jeurgens, E. Mittemeijer. The effect of pre-oxidation treatment on the corrosion behavior of amorphous $A l_{1-x} Z_{x}$ solid-solution alloys. Electrochim. Acta 188 (2016) 31. doi: 10.1016/j.electacta.2015.11.066.

[57] N. Buschow, K. H. J. and Beekmans. Thermal stability and electronic properties of amorphous Zr-Co and Zr-Ni alloys. Phys. Rev. B 19 (1979) 3843.

[58] H. Chen, K. Aust, Y. Waseda. Structural investigation of amorphous Fe$\mathrm{Zr}, \mathrm{Co}-\mathrm{Zr}$ and $\mathrm{Ni}-\mathrm{Zr}$ alloys with low zirconium concentration. J. Non. Cryst. Solids 46 (1981) 307. doi:10.1016/0022-3093(81)90008-9.

[59] Y. Dong, G. Gregan, M. Scott. Formation and stability of nickelzirconium glasses. J. Non. Cryst. Solids 43 (1981) 403. doi: 10.1016/0022-3093(81)90108-3.

[60] Z. Altounian, J. O. Strom-Olsen. Superconductivity and spin fluctuations in $\mathrm{M}$-Zr metallic glasses $(\mathrm{M}=\mathrm{Cu}, \mathrm{Ni}, \mathrm{Co}$, and Fe). Phys. Rev. B 27 (1983) 4149. doi:10.1103/PhysRevB.27.4149.

[61] Z. Altounian, T. Guo-hua, J. O. Strom-Olsen. Crystallization characteristics of $\mathrm{Ni}$ - Z $\mathrm{Zr}$ metallic glasses from $\mathrm{Ni}_{20} \mathrm{Zr}_{80}$ to $\mathrm{Ni}_{70} \mathrm{Zr}_{30}$. J. Appl. Phys. 54 (1983) 3111. doi:10.1063/1.332465.

[62] M. G. Karkut, R. R. Hake. Upper critical fields and superconducting transition temperatures of some zirconium-base amorphous transition-metal alloys. Phys. Rev. B 28 (1983) 1396. doi: 10.1103/PhysRevB.28.1396.

[63] K. H. J. Buschow. Short-range order and thermal stability in amorphous alloys. J. Phys. F Met. Phys. 14 (1984) 593. doi:10.1088/03054608/14/3/005.

[64] M. P. Henaff, C. Colinet, A. Pasturel, K. H. J. Buschow. Study of the enthalpies of formation and crystallization in the system $\mathrm{Zr}$-Ni. J. Appl. Phys. 56 (1984) 307. doi:10.1063/1.333963.

[65] D. L. Price, S. C. Moss, R. Reijers, M. L. Saboungi, S. Susman. Intermediate-range order in glasses and liquids. J. Phys. C Solid State Phys. 21 (1988) L1069. doi:10.1088/0022-3719/21/32/001.

[66] U. Mizutani, C. H. Lee. Effect of mechanical alloying beyond the completion of glass formation for Ni-Zr alloy powders. J. Mater. Sci. 25 (1990) 399. doi:10.1007/BF00714046.

[67] O. Haruyama, N. Asahi. Amorphization of mixed Ni and $\mathrm{Zr}$ powders by mechanical alloying. J. Alloys Compd. 194 (1993) 361. doi: 10.1016/0925-8388(93)90021-E.

[68] I. Bakonyi. Electronic properties and atomic structure of (Ti, Zr, Hf)(Ni, Cu) metallic glasses. J. Non. Cryst. Solids 180 (1995) 131. doi: 10.1016/0022-3093(94)00472-2.

[69] H. Jiang, J. Baram. Estimation of the glass transition temperature in metallic glasses. Mater. Sci. Eng. A 208 (1996) 232. doi:10.1016/09215093(95)10054-7.

[70] T. Fukunaga, K. Itoh, T. Otomo, K. Mori, M. Sugiyama, H. Kato,
M. Hasegawa, A. Hirata, Y. Hirotsu, A. C. Hannon. Voronoi analysis of the structure of $\mathrm{Cu}-\mathrm{Zr}$ and $\mathrm{Ni}-\mathrm{Zr}$ metallic glasses. Intermetallics 14 (2006) 893. doi:10.1016/j.intermet.2006.01.006.

[71] K. Georgarakis, A. R. Yavari, M. Aljerf, D. V. Louzguine-Luzgin, M. Stoica, G. Vaughan, A. Inoue. On the atomic structure of $\mathrm{Zr}$ $\mathrm{Ni}$ and $\mathrm{Zr}$-Ni-Al metallic glasses. J. Appl. Phys. 108 (2010) 1. doi: 10.1063/1.3446131.

[72] M. Ghidelli, S. Gravier, J.-J. Blandin, T. Pardoen, J.-P. Raskin, F. Mompiou. Compositional-induced structural change in $\mathrm{Zr}_{x} \mathrm{Ni}_{100-x}$ thin film metallic glasses. J. Alloys Compd. 615 (2014) S348. doi: 10.1016/j.jallcom.2013.12.054.

[73] M. Johnson, N. Mauro, A. Vogt, M. Blodgett, C. Pueblo, K. Kelton. Structural evolution and thermophysical properties of $\mathrm{Zr}_{x} \mathrm{Ni}_{100-x}$ metallic liquids and glasses. J. Non. Cryst. Solids 405 (2014) 211. doi: 10.1016/j.jnoncrysol.2014.10.026.

[74] H. Turnow, H. Wendrock, S. Menzel, T. Gemming, J. Eckert. Synthesis and characterization of amorphous $\mathrm{Ni}-\mathrm{Zr}$ thin films. Thin Solid Films 561 (2014) 48. doi:10.1016/j.tsf.2013.08.133.

[75] M. Apreutesei, P. Djemia, L. Belliard, G. Abadias, C. Esnouf, A. Billard, P. Steyer. Structural-elastic relationships of $\mathrm{Zr}-\mathrm{TL}(\mathrm{TL}=\mathrm{Cu}, \mathrm{Co}$, Ni) thin films metallic glasses. J. Alloys Compd. 707 (2017) 126. doi: 10.1016/j.jallcom.2016.12.208.

[76] Z. Altounian, T. Guo-hua, J. O. Strom-Olsen. Crystallization characteristics of $\mathrm{Cu}-\mathrm{Zr}$ metallic glasses from $\mathrm{Cu}_{70} \mathrm{Zr}_{30}$ to $\mathrm{Cu}_{25} \mathrm{Zr}_{75}$. J. Appl. Phys. 53 (1982) 4755. doi:10.1063/1.331304.

[77] Y. Calvayrac, J. P. Chevalier, M. Harmelin, A. Quivy, J. Bigot. On the stability and structure of Cu-Zr based glasses. Philos. Mag. B 48 (1983) 323. doi:10.1080/13642818308246485.

[78] D. Pavuna. On the concentration dependence of transport coefficients in amorphous transition metal alloys. Solid State Commun. 54 (1985) 771. doi:10.1016/0038-1098(85)90282-0.

[79] T. Minemura, J. J. van den Broek, J. L. C. Daams. Formation and thermal stability of amorphous $\mathrm{Cu}-\mathrm{Zr}$ thin films deposited by coevaporation. J. Appl. Phys. 63 (1988) 4426. doi:10.1063/1.340188.

[80] N. Mattern, U. Kühn, A. Concustell, A. Schops, M. D. Baro, J. Eckert. Phase Separation and Crystallization in Cu-Zr Metallic Glasses. Mater. Trans. 48 (2007) 1639. doi:10.2320/matertrans.MJ200708.

[81] Y. Li, Q. Guo, J. A. Kalb, C. V. Thompson. Matching Glass-Forming Ability with the Density of the Amorphous Phase. Science (80-. ). 322 (2008) 1816. doi:10.1126/science.1163062.

[82] N. Mattern, A. Schöps, U. Kühn, J. Acker, O. Khvostikova, J. Eckert. Structural behavior of $\mathrm{Cu}_{x} \mathrm{Zr}_{100-x}$ metallic glass $(x=35-70)$. J. Non. Cryst. Solids 354 (2008) 1054. doi:10.1016/j.jnoncrysol.2007.08.035.

[83] T. A. Baser, J. Das, J. Eckert, M. Baricco. Glass formation and mechanical properties of $\left(\mathrm{Cu}_{50} \mathrm{Zr}_{50}\right)_{100-x} A l_{x}(x=0,4,5,7)$ bulk metallic glasses. J. Alloys Compd. 483 (2009) 146. doi:10.1016/j.jallcom.2008.07.147.

[84] D. Ma, A. D. Stoica, X.-L. Wang. Power-law scaling and fractal nature of medium-range order in metallic glasses. Nat. Mater. 8 (2009) 30. doi: $10.1038 / \mathrm{nmat} 2340$

[85] M. I. Mendelev, M. J. Kramer, R. T. Ott, D. J. Sordelet, M. F. Besser, A. Kreyssig, A. I. Goldman, V. Wessels, K. K. Sahu, K. F. Kelton, R. W. Hyers, S. Canepari, J. R. Rogers. Experimental and computer simulation determination of the structural changes occurring through the liquid-glass transition in $\mathrm{Cu}-\mathrm{Zr}$ alloys. Philos. Mag. (2010). doi: 10.1080/14786435.2010.494585.

[86] I. Kalay, M. J. Kramer, R. E. Napolitano. High-Accuracy X-Ray Diffraction Analysis of Phase Evolution Sequence During Devitrification of $\mathrm{Cu}_{50} \mathrm{Zr}_{50}$ Metallic Glass. Metall. Mater. Trans. A 42 (2011) 1144. doi: 10.1007/s11661-010-0531-9.

[87] N. A. Mauro, A. J. Vogt, M. L. Johnson, J. C. Bendert, R. Soklaski, L. Yang, K. F. Kelton. Anomalous structural evolution and liquid fragility signatures in $\mathrm{Cu}-\mathrm{Zr}$ and $\mathrm{Cu}$-Hf liquids and glasses. Acta Mater. 61 (2013) 7411. doi:10.1016/j.actamat.2013.08.047

[88] L. Harris, B. M. Siegel. A Method for the Evaporation of Alloys. J. Appl. Phys. 19 (1948) 739. doi:10.1063/1.1698199.

[89] A. R. Yavari, J.-L. Uriarte, A. Inoue. Volume Effects in Amorphisation by Rapid Solidification and Solid State Reaction and in Bulk Glass-Forming Alloys. Mater. Sci. Forum 269-272 (1998) 533. doi: 10.4028/www.scientific.net/MSF.269-272.533.

[90] S. Gillani, S. Schulze, P. Häussler. Scenarios of structure stabilization and their cooperations in $A l_{100-x} M n_{x}$. J. Non. Cryst. Solids 447 (2016) 
290. doi:10.1016/j.jnoncrysol.2016.04.037.

[91] I. Bakonyi. Atomic volumes and local structure of metallic glasses. Acta Mater. 53 (2005) 2509. doi:10.1016/J.ACTAMAT.2005.02.016.

[92] K. Georgarakis, A. R. Yavari, D. V. Louzguine-Luzgin, J. Antonowicz, M. Stoica, Y. Li, M. Satta, A. Lemoulec, G. Vaughan, A. Inoue. Atomic structure of $\mathrm{Zr}$-Cu glassy alloys and detection of deviations from ideal solution behavior with Al addition by $x$-ray diffraction using synchrotron light in transmission. Appl. Phys. Lett. 94 (2009) 48. doi: 10.1063/1.3136428.

[93] R. Ristić, J. Cooper, K. Zadro, D. Pajić, J. Ivkov, E. Babić. Ideal solution behaviour of glassy $\mathrm{Cu}-\mathrm{Ti}, \mathrm{Zr}, \mathrm{Hf}$ alloys and properties of amorphous copper. J. Alloys Compd. 621 (2015) $136 . \quad$ doi: 10.1016/j.jallcom.2014.09.167.

[94] J. Eckert, J. Das, K. Kim, F. Baier, M. Tang, W. Wang, Z. Zhang. High strength ductile Cu-base metallic glass. Intermetallics 14 (2006) 876. doi:10.1016/J.INTERMET.2006.01.003.

[95] A. Inoue, W. Zhang. Formation, Thermal Stability and Mechanical Properties of $\mathrm{Cu}-\mathrm{Zr}$ and $\mathrm{Cu}$-Hf Binary Glassy Alloy Rods. Mater. Trans. 45 (2004) 584. doi:10.2320/matertrans.45.584

[96] T. Mei-Bo, Z. De-Qian, P. Ming-Xiang, W. Wei-Hua. Binary Cu-Zr Bulk Metallic Glasses. Chinese Phys. Lett. 21 (2004) 901. doi:10.1088/0256307X/21/5/039.

[97] D. Wang, Y. Li, B. B. Sun, M. L. Sui, K. Lu, E. Ma. Bulk metallic glass formation in the binary Cu-Zr system. Appl. Phys. Lett. 84 (2004) 4029. doi:10.1063/1.1751219.

[98] D. Xu, B. Lohwongwatana, G. Duan, W. L. Johnson, C. Garland. Bulk metallic glass formation in binary Cu-rich alloy series - $C u_{100-x} \mathrm{Zr}_{x}$ $\left(x=34,36,38.2,40\right.$ at.\%) and mechanical properties of bulk $\mathrm{Cu}_{64} \mathrm{Zr}_{36}$ glass. Acta Mater. 52 (2004) 2621. doi:10.1016/j.actamat.2004.02.009.

[99] Y. Wang, J. Yao, Y. Li. Glass formation adjacent to the intermetallic compounds in $\mathrm{Cu}-\mathrm{Zr}$ binary system. J. Mater. Sci. Technol. 34 (2018) 605. doi:10.1016/j.jmst.2017.09.008.

[100] A. Amamou, G. Krill. Photoemission on a Cu-Zr glassy metal. Solid State Commun. 28 (1978) 957. doi:10.1016/0038-1098(78)90120-5.

[101] P. Oelhafen, E. Hauser, H. J. Güntherodt, K. H. Bennemann. New Type of d-Band-Metal Alloys: The Valence-Band Structure of the Metallic Glasses Pd-Zr and Cu-Zr. Phys. Rev. Lett. 43 (1979) 1134. doi: 10.1103/PhysRevLett.43.1134.

[102] A. Amamou. $d$ Band structure and alloying effects in crystalline and amorphous Zr-Co and Zr-Ni. Solid State Commun. 33 (1980) 1029. doi: 10.1016/0038-1098(80)90311-7.

[103] P. Steiner, M. Schmidt, S. Hüffner. Photoemission study of Pd Zr and Cu Zr alloys. Solid State Commun. 35 (1980) 493. doi:10.1016/00381098(80)90255-0.

[104] S. Falch, G. Rainer-Harbach, F. Schmückle, S. Siegfried. Electronic Structure of Metallic Glasses from the $\mathrm{Cu}-\mathrm{Zr}$ - and $\mathrm{Cu}$-Ti-Systems as well as from some Transitionmetall-Metalloid-Systems by Means of X-RayEmission Spectroscopy. Zeitschrift fur Naturforsch. - Sect. A J. Phys. Sci. 36 (1981) 937. doi:10.1515/zna-1981-0903.

[105] W. Yang, H. Liu, Q. Wang, Z. Wei, L. Xue, C. Dun, Y. Zhao, C. Chang, B. Shen. Electronic structure of $C u_{100-x} Z r_{x}(x=40,50,60)$ metallic glasses. Mater. Des. 82 (2015) 126. doi:10.1016/j.matdes.2015.05.066.

[106] S. Hosokawa, H. Sato, M. Nakatake, H. Kato. Electronic structures and heterogeneity of $\mathrm{Zr}-\mathrm{Cu}-\mathrm{Ag}$ metallic glasses. J. Non. Cryst. Solids 498 (2018) 281. doi:10.1016/j.jnoncrysol.2018.06.036.

[107] E. Babić, R. Ristić, I. Figueroa, D. Pajić, Ž. Skoko, K. Zadro. Electronic structure and glass forming ability in early and late transition metal alloys. Philos. Mag. 98 (2018) 1. doi:10.1080/14786435.2017.1415467.

[108] T. E. Faber, J. M. Ziman. A theory of the electrical properties of liquid metals. Philos. Mag. 11 (1964) 153. doi:10.1080/14786436508211931.

[109] R. Evans, D. A. Greenwood, P. Lloyd. Calculations of the transport properties of liquid transition metals. Phys. Lett. 35 (1971) 57. doi: 10.1016/0375-9601(71)90543-3.

[110] P. L. Rossiter. The Electrical Resistivity of Metals and Alloys (Cambridge Solid State Science Series) (Cambridge, 1991). ISBN 9780521408721.

[111] N. F. Mott. The electrical resistivity of liquid transition metals. Philos. Mag. 26 (1972) 1249. doi:10.1080/14786437208220339.

[112] M. Howson. The electron transport properties of metallic glasses. Phys. Rep. 170 (1988) 265. doi:10.1016/0370-1573(88)90145-7.

[113] K.-W. Park, J.-i. Jang, M. Wakeda, Y. Shibutani, J.-C. Lee. Atomic packing density and its influence on the properties of $\mathrm{Cu}$-Zr amorphous alloys.
Scr. Mater. 57 (2007) 805. doi:10.1016/j.scriptamat.2007.07.019.

[114] P. Häussler, R. Haberkern, C. Madel, J. Barzola-Quiquia, M. Lang. On the formation of quasicrystals and the evolution of transport anomalies. J. Alloys Compd. 342 (2002) 228. doi:10.1016/S0925-8388(02)00201-3.

[115] J. Barzola-Quiquia, M. Stiller, M. Stiehler, P. Esquinazi, P Häussler. Structural, magnetic and electronic transport properties of amorphous and quasicrystalline $\mathrm{Al}_{70} \mathrm{Pd}_{20} \mathrm{Fe}_{10}$ thin films. Mater. Res. Express 2 (2015) 096403. doi:10.1088/2053-1591/2/9/096403.

[116] Y. Cheng, E. Ma. Atomic-level structure and structure-property relationship in metallic glasses. Prog. Mater. Sci. 56 (2011) 379. doi: 10.1016/j.pmatsci.2010.12.002

[117] J. Ding, E. Ma. Computational modeling sheds light on structural evolution in metallic glasses and supercooled liquids. npj Comput. Mater. 3 (2017) 9. doi:10.1038/s41524-017-0007-1.

[118] J. Ding, Y. Q. Cheng, E. Ma. Full icosahedra dominate local order in $\mathrm{Cu}_{64} \mathrm{Zr}_{34}$ metallic glass and supercooled liquid. Acta Mater. 69 (2014) 343. doi:10.1016/j.actamat.2014.02.005.

[119] A. Inoue, T. Zhang, T. Masumoto. Zr-Al-Ni Amorphous Alloys with High Glass Transition Temperature and Significant Supercooled Liquid Region (1990). doi:10.2320/matertrans 1989.31.177.

[120] L. Xing, P. Ochin, J. Bigot. Effects of Al on the glass-forming ability of $\mathrm{Zr}$-Cu based alloys. J. Non. Cryst. Solids 205-207 (1996) 637. doi: 10.1016/S0022-3093(96)00382-1.

[121] J. Antonowicz, D. Louzguine-Luzgin, A. Yavari, K. Georgarakis, M. Stoica, G. Vaughan, E. Matsubara, A. Inoue. Atomic structure of $\mathrm{Zr}-\mathrm{Cu}-\mathrm{Al}$ and $\mathrm{Zr}$-Ni-Al amorphous alloys. J. Alloys Compd. 471 (2009) 70. doi: 10.1016/j.jallcom.2008.03.092.

[122] I. Kaban, P. Jóvári, V. Kokotin, O. Shuleshova, B. Beuneu, K. Saksl, N. Mattern, J. Eckert, A. Greer. Local atomic arrangements and their topology in $\mathrm{Ni}-\mathrm{Zr}$ and $\mathrm{Cu}-\mathrm{Zr}$ glassy and crystalline alloys. Acta Mater. 61 (2013) 2509. doi:10.1016/j.actamat.2013.01.027.

[123] K. Georgarakis, L. Hennet, G. A. Evangelakis, J. Antonowicz, G. B. Bokas, V. Honkimaki, A. Bytchkov, M. W. Chen, A. R. Yavari. Probing the structure of a liquid metal during vitrification. Acta Mater. 87 (2015) 174. doi:10.1016/j.actamat.2015.01.005.

[124] C. Lekka, G. Evangelakis. Bonding characteristics and strengthening of $\mathrm{CuZr}$ fundamental clusters upon small Al additions from density functional theory calculations. Scr. Mater. 61 (2009) 974. doi: 10.1016/j.scriptamat.2009.08.008.

[125] A. K. Bhatnagar, K. W. Rhie, D. G. Naugle, A. Wolfenden, B. H. Zhang, T. O. Callaway, W. D. Bruton, C. R. Hu. The effect of simple metal $(\mathrm{Al}, \mathrm{Ga}$ ) addition on the crystallisation and density of amorphous $\mathrm{Zr}$ Ni alloys. J. Phys. Condens. Matter 2 (1990) 2625. doi:10.1088/09538984/2/11/008

[126] A. Inoue, T. Zhang. Fabrication of Bulk Glassy $\mathrm{Zr}_{55} \mathrm{Al}_{10} \mathrm{Ni}_{5} \mathrm{Cu}_{30}$ Alloy of $30 \mathrm{~mm}$ in Diameter by a Suction Casting Method. Mater. Trans. JIM 37 (1996) 185. doi:10.2320/matertrans1989.37.185. 
2018-12-12

\section{On the impact of global interactions on the structure of metallic glasses}

Stiehler, Martin E.

Elsevier

Stiehler ME, Jolly MR, Georgarakis K. On the impact of global interactions on the structure of metallic glasses. Journal of Alloys and Compounds, Volume 782, April 2019, pp. 496-505 https://doi.org/10.1016/j.jallcom.2018.12.086

Downloaded from Cranfield Library Services E-Repository 